\title{
EREBEA
}

Revista de Humanidades

y Ciencias Sociales

Núm. 4 (2014), pp. 325-352

ISSN: 0214-0691

\section{DE LAS RAZAS HISTÓRICAS AL RACISMO ELEGANTE. NuEVAS PERSPECTIVAS PARA UN DEBATE HUMANÍSTICO URGENTE*}

\author{
José Antonio González Alcantud \\ Universidad de Granada
}

\section{RESUMEN}

El racismo biológico quedó desacreditado casi desde su propio nacimiento. Su sustituto, con todos los marchamos de honorabilidad académica, fue el "racismo cultural", que en el fondo sirve para jerarquizar a los grupos sociales y "étnicos" en una pirámide civilizatoria. La corriente llamada "psychologie des peuples ", después de la II Guerra Mundial, ha heredado en buena medida el "racismo cultural", al clasificar a los pueblos europeos sobre todo en función de ciertos caracteres culturales fijos. Hoy día el antirracismo es un lugar común el discurso social y político, pero en su versión cultural sigue marcando la vida social gracias a su invisibilidad.
Palabras Clave

Raza biológica, raza cultural, invisibilidad, discurso, "psychologie des peuples", multiculturalismo.

\section{ABSTRACT}

Biological racism was rejected from his own birth. It was replaced by the "cultural racism”, with a great academic acceptation. But "cultural racism" is used to organize a hierarchy the social and "ethnical" groups into a pyramid of Civilization. The tendency called "Psychologie des Peuples" has inherited, after the II World War, to the cultural racism, because it has classified the European people following preestablished pattern. Today antiracism is a common topic in the social and political discourse, but in its cultural version it still influences social life due to its invisibility.

Fecha de recepción: 14 de mayo de 2014

Fecha de aceptación: 23 de octubre de 2014

* Las ideas aquí desarrolladas fueron expuestas con motivo de la conferencia inaugural del curso 2010/2011 de la Facultad de Filosofía de la Universidad de Murcia. Le agradezco al profesor Luis Álvarez Munárriz esta invitación. Algunos otros argumentos fueron explicitados ulteriormente en forma de libro: J.A. González Alcantud. Racismo elegante. De la teoría de las razas culturales a la invisibilidad del racismo cotidiano. Barcelona: Bellaterra, 2011. 

El racismo interpretado en sus dimensiones "elegante", "simbólica", "invisible" o cualquiera otra que enfatice su permanencia en el tiempo, a pesar de la emancipación de la cuestión biológica, es un tema de la máxima actualidad. Al racismo nos vamos a remitir una vez más, por ser inagotable manantial de reflexión, a pesar de que el vocablo "racismo" manoseado en exceso en manos de los medios de comunicación quizás haya contribuido a desdibujar la profundidad de su problematicidad.

El racismo tiene su antes y después. Si como sostiene la filosofía, el Holocausto marca una frontera nítida en el pensamiento contemporáneo, no es sólo por la barbarie de su hacer, sino igualmente porque, según Z. Bauman, su trascendencia concierne no solo a la cuestión judía. La existencia de los lager nos remite a la noción misma de Modernidad. Es decir, la shoah no fue un gran pogromo, plagado de problemática emocional, sino la directa consecuencia del funcionamiento racional y frío de la burocracia ${ }^{1}$. Y quizás, aventuramos, ocurra algo similar con el racismo.

Todavía en los años setenta el antirracismo, sobre todo estadounidense, respiraba un tufo claramente revolucionario. Basta contemplar las fotografías que de la segregación racial en la universitaria Boston se pueden ver hoy día en el museo negro de Beacon Hill de esta ciudad, para hacernos conscientes de la magnitud y crueldad del segregacionismo racial norteamericano en medio tan educado, y $\tan$ democrático por ende. Pocos años después de los combates antisegregacionistas ocurridos en Estados Unidos y en Sudáfrica, la raza y el racismo en general se convertirían en el leitmotiv de numerosas movilizaciones intelectuales y cívicas desposeídas de aspiración revolucionaria alguna: se trataba sólo de pedir la integración en lo existente. La primera marcha masiva de SOS Racisme en 1985, en la plaza de la Concorde, en París tuvo todas las características de las grandes movilizaciones de tres lustros antes, las sesentayochistas, pero sin tener enfrente a ningún enemigo histórico como la gran burguesía o la plutocracia gaullistas. En realidad, era un pronunciamiento público sin nadie a quien reclamar. Vivre ensemble avec nos différences rezaban las chapas que fueron repartidas. Demasiado educado todo. Como escribió en su momento P.A. Taguieff, "la aparición reciente, en Francia, de movilizaciones antirracistas de masas, ha contribuido a la desproblematización 
del antirracismo", y ello fundamentalmente "porque el antirracismo mediático ha precedido y preparado las movilizaciones anti-excluyentes teatralizadas"2. En su lucha contra el antirracismo educado Taguieff sostendrá que no basta con expulsar la palabra "raza" de nuestro lenguaje cotidiano para acabar con el problema ${ }^{3}$. Algo no funciona en tantos actos de buena voluntad, y la falla no acaba de ser localizada. Por ejemplo, que a la raza de base biológica le ha seguido algo más inasible y espiritual, si se quiere, como es la distinción social y cultural -tal como lo piensa Pierre Bourdieu-, en tanto base de las "razas culturales".

Avancemos a este tenor algo del caso más sintomático. El etnólogo Alfred Métraux, un viejo conocido de Claude Lévi-Strauss desde la época en que ambos encarnaban con otros intelectuales la oposición intelectual al nazismo exiliada en Estados Unidos, comenzó a editar en 1950, en el momento en que era director de la oficina de relaciones raciales de la UNESCO, y coincidiendo con un coloquio sobre el racismo convocado por esta institución, una colección titulada "La cuestión racial ante la ciencia moderna”. A petición suya Lévi-Strauss escribirá un discurso titulado Race et Histoire $e^{4}$. En este librito, Lévi-Strauss establecía la distinción capital, que luego retomaría en otra obra de mayor enjundia, La Pensée Sauvages, entre sociedades "frías" y sociedades "calientes", dejando claro que el desarrollo tecnológico y civilizatorio no respondía a criterios de superioridad cultural o racial, sino de particularidades o incluso de elección; ahondaba, por consiguiente, en el relativismo cultural, y lo elevaba científicamente a categoría axiológica. Race et Histoire se convirtió de inmediato en un clásico del antirracismo, e incluso pasó al dominio público de los estudiantes de bachillerato y de sus profesores, que lo leían en clave moral, sin acabar de comprender del todo su significado. Era un ícono político. La lucha contra el racismo había así alcanzado una gran popularidad, pero no una profunda comprensión.

Lévi-Strauss no se sintió paradójicamente satisfecho con esta aceptación popular, que venía a simplificar con argumentos morales la complejidad de las tesis científicas ${ }^{6}$. Para responder a esta simplificación, y "para no repetirse", LéviStrauss volvió al tema, en 1971, también a petición de la UNESCO. La conferencia, ahora llamada Race et Culture, escandalizó a quienes se la encargaron al no responder a sus expectativas e incluso cuestionarlas. En esta disertación Lévi-Strauss, a su vez preocupado por la interpretación simplista de sus teorías, se muestra tajante sobre la imposibilidad de la antropología cultural para acercarse satisfactoriamente a la noción de raza biológica: "No le corresponde al etnólogo

2 Pierre-André Taguieff. Les fins de l'antiracisme. París: Eds. Michalon, 1997, p.II.

3 Ibidem, p.333.

4 J.A. González Alcantud. El 'combate' contra el racismo en Claude Lévi-Strauss”. Historia, Antropologia y Fuentes Orales, no 43, 2010, pp. 21-38. Reproducido en Racismo elegante...op.cit.

5 Claude Lévi-Strauss. La pensée sauvage. París : Plon, 1962.

6 Claude Lévi-Strauss \& Didier Eribon. De cerca y de lejos. Madrid: Alianza, 1990. 
tratar de decir lo que es o no es una raza, porque los especialistas de la antropología física, que lo vienen discutiendo desde hace casi dos siglos, jamás se han puesto de acuerdo, y nada indica que estén hoy más cerca de hacerlo"7. Para LéviStrauss está relativamente claro lo que es una cultura, ya difícil de definir por sí misma, pero no lo qué significa una raza, dado que los enigmas que plantea son aún mayores. Así interpretó él mismo a posteriori el objetivo que buscaba con la provocación del escándalo:

"Durante esos veinte años habían pasado muchas cosas, entre ellas, por lo que a mí se refiere, una irritación creciente ante una ostentación periódica de buenos sentimientos como si con eso bastase. Me parecía, por el contrario, de un lado que los conflictos racionales no hacían más que agravarse; de otro, que, en el espíritu del público se creaba una confusión en torno a nociones tales como las de racismo y antirracismo, y que a fuerza de ampliarlas de forma inconsiderada se alimentaba el racismo en lugar de debilitarlo"

En función de lo anterior, es decir de la insatisfacción que provocan las políticas de buena conciencia y autosatisfacción antirracista, se impone reflexionar de nuevo sobre el porqué de la persistencia del racismo ideológico, y repensar en consecuencia sus orígenes.

\section{Las "Razas Históricas” como alternativa “Antirracista” a las Razas BiolÓgICAS}

1.1. GÉNESIS DE la teOría de las RAZAS históricas: FouIlléE y Le BoN

Una vez más hemos de mirar a Francia, encarnación del ideal ilustrado, para encontrar una explicación al reto propuesto. Francia ocupa un lugar fundacional en la búsqueda para encontrar unas características antropológicas de base racial a la nación. Entre los primeros trabajos llevados a cabo allá sobre esta materia tenemos los de Paul Broca Recherches sur l'ethnologie de la France, aparecido en 1859, y de Gustave Lagneau Notice questionnaire sur l'anthropologie de la France, de 1861. Broca, respondiendo a las cuestiones planteadas por Gobineau, considera que la raza francesa no estaba degenerando como algunos agoreros señalaban, entre ellos Gobineau, ya que las « transformaciones no pueden tener lugar más que una extrema lentitud, por la superposición de un gran número de generaciones " ${ }^{9}$. Luego vinieron a fines de siglo los trabajos de Mortillet en 1897

7 Claude Lévi-Strauss. Raza y cultura. Madrid: Cátedra. Introducción y edición de Manuel Garrido, p.107.

8 Ibidem, p.203.

9 Paul Broca. Sur la prétendue dégénérescence de la population française. París : Imprimerie E.Martinet, 1867, p.49. 
con su Formation de la nation française. Ninguno de ellos resolvió el problema de la existencia de una supuesta "raza francesa", ya que la realidad nacional de Francia inducía automáticamente a pensar en la pluralidad racial del pueblo francés.

Por supuesto, quien ha recibido más ataques en el ámbito de los combates sociales contra el racismo, hasta convertirse en su expresión más estereotipada, fue el también francés Arthur Gobineau. Las motivaciones de Gobineau para tramar su reflexión raciológica parecen responder a una cuestión interna. Cuando escribió su célebre libro sobre la desigualdad, el Essai sur linégalité des races bumaine (1853), donde se mostraba contrario a toda mezcla racial por albergar ésta el principio de la degeneración, sentía un profundo " odio, desprecio y horror (...) hacia el mundo contemporáneo", y el que éste "fuese infinitamente más virulento [en 1877], como lo era en 1850 , y es verosímil que extendiese sobre el pasado, en cierta medida, los sentimientos que lo animaban en el momento presente". Es decir, el ensayo gobineauniano habría nacido en gran medida, "de la decepción que inspiraba a Gobineau el espectáculo de su época ${ }^{10}$. Para Gobineau la separación física y cultural de las razas es un hecho; ataca en este terreno a los "unitaristas" que querían ver un único origen para todo el género humano. Tampoco está convencido de que sea el clima o el lugar el argumento definitivo que explique las diferencias entre unas razas y otras. Confiere una dimensión más trascendente a la civilización, y en consecuencia a los hechos culturales en sí mismos. No siendo, por lo demás, la nuestra la civilización más elaborada, ya que tenemos modelos anteriores que nos superan, la "degeneración" sería la palabra clave para explicar estos vaivenes de la historia, y ésta estaría fundada en la existencia de mezclas que provocarían el estado de decadencia:

"Yo pienso entonces que la palabra 'degenerado', aplicándola a un pueblo, debe significar y significa que este pueblo no tiene el valor intrínseco que anteriormente tenía porque él no tiene en sus venas la misma sangre, en la cual las alianzas sucesivas han modificado gradualmente su valor"11.

A Gobineau le preocupaba como causa de la degeneración, además de la mezcla, la "corrupción de costumbres". Razonaba así: "La corrupción de costumbres, en sí misma la más horrible de las plagas, no juega inevitablemente un papel destructor", ya que esta decadencia que entrañaría la corrupción estaría en relación con las fluctuaciones de la propia historia nacional, y no de de las "virtudes de los primeros romanos", es decir de algo fijo e inmutable, heroico ${ }^{12}$.

$10 \mathrm{~J}$. Buenzot, La formation de la pensée de Gobineau et l'Essai sur l'inégalité des races humaines. París : Librairie A.G. Nizet, 1967, p.329.

11 Arthur M. Gobineau. "Essai sur l'inégalité des races humaines » (1853). A. Gobineau. Euvres. I. París : NRF, Bibliothèque de la Pléiade, 1983, p.162.

12 Ibidem, p.148. 
Gobineau ha quedado en buena medida reducido a estas ideas, y por ellas es ampliamente conocido, encarnando a la perfección el modelo del raciólogo intelectual. Sin embargo, se olvidan otras dimensiones de su racismo, desarrollado en las casi mil páginas del Essai sur l'inégalité des races humaine. Se olvida, por ejemplo, el racismo que hoy día podríamos catalogar de lingüístico, cuyo debate Gobineau abre. Proclamará este axioma sobre el particular, relacionando la lógica de las razas con la de las lenguas: "La jerarquía de las lenguas corresponde rigurosamente a la jerarquía de las razas" ${ }^{3}$. Sólo partiendo de ese axioma podríamos arribar a nuevas y fértiles conclusiones sobre las lenguas y la jerarquización sociocultural actual, sobre todo en relación con la supremacía del inglés ${ }^{14}$.

Descartado todo racismo biológico como fundamento de la nación revolucionaria, el hecho nacional es interpretado muy tempranamente en clave culturalista entre los intelectuales franceses. Las obras de HyppoliteTaine y de Ernest Renan dominan todo el paisaje intelectual hasta el fin de siglo. La posición en particular de Taine se desarrolla en su Histoire de la Littérature anglaise. La idea de "raza" está presente en todos los estudios que este consagra a la filosofía del arte. "La noción de raza le ayuda (...) a definir el genio estético de cada uno de los pueblos que aborda en sus obras» ${ }^{15}$. Renan, por su parte, creía en el genio francés tramado en la cultura. Taine y Renan ejercerían su influencia sobre el pensamiento del escritor Barrès y del sociólogo Gustave Le Bon, ambos conservadores. Esta ideología del genio de la raza cultural jugará un papel de gran importancia en el largo trabajo de zapa a la cultura política basada en el racionalismo ilustrado y revolucionario. El determinismo cultural se va abriendo de esta manera paso ${ }^{16}$. La visión conservadora basada en el concepto de " raza cultural " permearía toda la ideología y comportamientos colectivos de Francia durante buena parte del siglo $\mathrm{XX}$, convirtiéndose en uno de los soportes más claros de la ideología de la hoy llamada «república colonial», al socavar los principios igualitarios de la Revolución francesa, y privilegiar supremacía de la "raza francesa"17.

El iniciador de la llamada "psicología de los pueblos", que tenía en el horizonte al concepto de "raza cultural", fue Émile Boutmy (1835-1909). Éste era discípulo directo de Hyppolite Taine. Siguió literalmente al maestro al situar el « alma colectiva " en el centro de su pensamiento. El alma colectiva, concepto

13 Ibidem, p.339.

14 J.A. González Alcantud. Politicas del sentido. Los combates por la significación en la posmodernidad. Barcelona: Anthropos, 2000.

15 François Léger. "Lidée de race chez Taine". In: Émile Temime \& Pierre Guiral. Lidée de race dans la pensée politique française contemporaine. París : Eds. du CNRS, 1977, p.91.

16 Zeev Sternhell. "La fonction politique et culturelle du racisme". In: Michel Wieviorka (ed.) Racisme et modernité. París: La Découverte, 1992, p.57.

17 J.A. González Alcantud. La fábrica de los estereotipos. Francia, nosotros y la europeidad. Madrid : Abada, 2006. 
rápidamente asumido por prensa y literatos que la reprodujeron $a b$ nauseam, "es percibida - por Boutmy- como el producto de las condiciones físicas originales que se imponen a cada población $»^{18}$. Bajo este criterio escribirá dos obras : Essai d'une psychologie politique du peuple anglais au XIXè siècle (1901), y Eléments d'une psychologie politique du peuple américain (1902). En la primera de estas obras, comienza subrayando, al modo de Taine, la importancia, del medio físico. No obstante, dará un giro importante a su argumentación al sostener que «el gusto y el hábito del esfuerzo deben ser considerados como el atributo esencial, la cualidad profunda y espontánea de la raza ${ }^{19}$, lo cual destacaría él como un signo distintivo de la raza anglosajona. Boutmy, vinculando su idea racial al concepto de "casta", razona siempre con el pensamiento en Inglaterra, que:

«Las causas que han introducido la necesidad de actividad en este tipo de la raza han perdido hoy día su intensidad. La multiplicación de los capitales intelectuales y materiales han aumentado el número de personas muy ricas, debilitando gradualmente, en una parte de la masa nacional, el instinto hereditario por el cual el hombre reconoce y acepta la ley del trabajo. De otro, en este medio nuevo, los indolentes y los débiles han tenido suerte de subsistir, de perpetuarse y de constituir un elemento étnico permanente» ${ }^{20}$.

Por consiguiente para el iniciador de la psicología de los pueblos el principio estructurador sería la "raza ", en tanto casta aristocrática, si bien en ésta el trabajo sea parte sustancial, en lugar de la nación o el pueblo de formación igualitaria.

Empero el autor en quien los debates sobre la "raza" y sus relaciones con la cultura y/o la civilización alcanzarán mayor densidad y redondez fue Alfred Fouillée (1838-1912). El concepto dominante en Fouillée, por el que será más conocido en su época, es el de "ideas-fuerza", noción típicamente idealista, donde la voluntad de poder se convierte en el trasunto de toda la historia. Se expresa en estos términos a propósito del papel de la voluntad, de la "consciencia" según él, en la historia:

"'Voluntad de consciencia', tal es la fórmula que, en nuestra Morale des idées-forces, habíamos ya propuesto y que propondremos de nuevo para expresar el fondo de la existencia. Nos parece necesario tomar de la filosofía de Schopenhauer y de sus continuadores: voluntad de...; nosotros

18 Philippe Claret. La personalité collective des nations. Théories anglo-saxones et conceptions françaises du caractère nacional. Bruselas :Bruylant, 1998, p.89.

19 Émile Boutmy. Essai d'une psychologie politique du peuple anglais au XIXe siècle. París : Librairie Armand Colin, 1901, p.14.

20 Ibidem, p.14. 
destacamos así nuestra oposición a aquellos que consideran más la voluntad de vida, o la voluntad de poder, o incluso la voluntad de acción práctica”21.

El sujeto, según Fouillée, se percibiría a sí mismo como voluntad: "Yo quiero ser para mí, yo quiero ser consciente; mi voluntad es entonces, en última instancia, voluntad de consciencia"22. Esta percepción del mundo influiría en muchas teorías vitalistas e idealistas, como la del pensador español Ángel Ganivet.

Por otra parte, las concepciones sobre la jerarquía de Fouillée estaban orientadas por el evolucionismo, con todas sus connotaciones darwinistas de lucha por la supervivencia: "En resumen -arguye-, la biología, la sociología, la política, la moral misma, están de acuerdo; la evolución orgánica está en armonía con la evolución social, la clasificación de los organismos con la clasificación de las sociedades" 23 . Pero este mecanicismo evolucionista paradójicamente no compromete la idea de libertad, según Fouillée. Al igual que la evolución tampoco presupondría el acceso automático a superiores niveles colectivos de justicia y bondad social: "La evolución -continúa argumentando- no presupone la paz, la justicia, la moralidad, sino que ella los produce; y lo hace de dos maneras: $1^{\circ}$ por el desarrollo del interés y la simpatía, del egoísmo y del altruismo racionales; 2o por la influencia de las ideas, es decir por la tendencia del ideal a realizarse en la medida en que es concebido" ${ }^{24}$. La interpretación fouilleana del evolucionismo no lleva implícita la supremacía del progreso: "La evolución entre los seres inteligentes y sensibles, no puede aparecer como siendo al mismo tiempo un progreso, puesto que el progreso en el fondo no es más que la evolución misma de la inteligencia y de la sensibilidad hacia un máximo que será su estado límite, en otros términos, la variación en el sentido de un engrandecimiento del pensamiento y el bienestar" 25 . Hasta aquí su interpretación de la interacción determinismo/libertad.

En otro orden, Fouillée cree que todo encuentra su explicación definitiva en la medida en que existe un "inconsciente colectivo" que ha venido a sustituir eficazmente las anteriores explicaciones de "derecho divino". Arguye que si bien, "la explicación más antigua y más popular que nos proponen los partidarios de la finalidad, es admitir una suerte de Providencia superior a las sociedades humanas, que les hace servir, sin que ellas lo sepan, a sus impenetrables destinos", "la explicación más moderna consiste en hacer descender esta Providencia al seno

21 Alfred Fouillée. La pensée et les nouvelles écoles anti-intellectualistes. París: Felix Alcan, 1927, 5 a, p.II.

22 Ibidem, p.14.

23 Alfred Fouillée. La Science Sociale Contemporaine. París : Hachette, 1910, p.191.

24 Ibidem, p. 185

25 Ibidem, p.186. 
mismo de las naciones, bajo la forma de una 'voluntad inconsciente"”26. Para finalizar, este inconsciente, siendo algo "más que un desplazamiento o dispersión de la conciencia", puesto que "en lugar de concentrarse en la parte directora, se expande en las partes dirigidas", se transforma en una "psicología colectiva" 27. Estudiar esa psicología colectiva para averiguar el lugar de cada pueblo en la evolución parece elemental. De esta evolución psicológica se desprende una jerarquía que organiza la vida internacional ${ }^{28}$.

Junto a las ideas de Alfred Fouillée algunas otras sobre el papel de las mentalidades colectivas en la formación de la idea de "raza" se las debemos a su coetáneo: Gustave Le Bon (1841-1931). Le Bon escribió una obra que sigue siendo de referencia en el campo de la psicología: La Psychologie des Foules (1895). El estado irracional en el que sitúa las acciones colectivas de las masas tuvo mucha fortuna interpretativa. Sus consideraciones elitistas y jerárquicas sobre el comportamiento irracional e ilógico de la masa, fácil presa de las pasiones en una época en que el igualitarismo socialista estaba en alza, tuvieron gran aceptación en su tiempo. En un trabajo de síntesis como fue las Lois psychologiques de l'évolution des peuples, publicado en 1894, y del cual en 1927 se habían hecho dieciocho ediciones, Fouillée afirma que « la vida de los pueblos está regida por un pequeño número de factores psicológicos invariables " ${ }^{29}$. Tajantemente afirma: "Cada raza posee una constitución mental tan fija como su constitución física $»^{30}$. Ligando esta última afirmación a la concepción racial sigue razonando:

«Poco influenciados por la inteligencia, los pueblos están sobre todo guiados por los caracteres de su raza, es decir por un agregado hereditario de sentimientos, deseos, costumbres, tradiciones, aspiraciones que representan los fundamentos esenciales del alma de las naciones. Este alma nacional da a los pueblos una estabilidad duradera a través de las perpetuas fluctuaciones de las contingencias. Y aquí tocamos con el sustrato invisible de la historia, con las fuerzas secretas que orientan su curso. Es la raza en efecto quien determina la manera en la que los pueblos renacen bajo la influencia de los acontecimientos y los cambios de medio. Dominando las instituciones y los códigos pero también las voluntades de los déspotas, el alma de las razas rige sus destinos. Su conocimiento permite descifrar

26 Ibidem, p.197.

27 Ibidem, p.206.

28 Alfred Fouillée. Esquisse psychologique des peuples européens. París : Felix Alcan, 20 ed.1903. Alfred Fouillée. Psychologie du peuple français. París : Felix Alcan. 3ºed. 1903.

29 Gustave Le Bon. Lois pyschologiques de l'evolution des peuples. (orig. 1894). Aphorismes $d u$ temps présent. L'incertitude de l'heure présente. París : Les Amis de Gustave Le Bon, 1978 (orig.1913 y 1924), p.1.

30 Ibidem, p.16. 
los jeroglíficos de la historia (...) La raza es la piedra angular sobre la cual reposa el equilibrio de las naciones» ${ }^{31}$.

La raza para Gustave Le Bon es la " raza histórica », con énfasis en esto último: "Las razas históricas, es decir las razas artificiales formadas desde los tiempos históricos por los azares de las conquistas políticas " ${ }^{32}$. Para Le Bon está claro, por lo demás, que lo fisiológico nos ilumina poco para lo que a él en realidad le interesa, o sea definir históricamente la raza en toda su profundidad:

«Los caracteres anatómicos (...), no permiten más que análisis bastante sumarios. Sus divergencias aparecen solamente en las especies humanas bien separadas: los blancos, los negros y los amarillos, por ejemplo. Pero pueblos, muy semejantes por su aspecto físico, pueden diferir grandemente en su manera de sentir y de tratar, y en consecuencia, por sus civilizaciones, sus creencias y sus artes» ${ }^{33}$.

La finalidad político-intelectual de Le Bon al exhumar la idea de "raza histórica", y, la que le es contigua, de "civilización", es oponerse al socialismo emergente. De éste hace igualmente un análisis "psicológico", similar al que el antropólogo físico Cesare Lombroso había realizado sobre el anarquismo, considerándolo una patología que afectaba a las grandes naciones, y en definitiva a las razas, contribuyendo sustancialmente a su degradación.

Gustave Le Bon, como Alfred Fouillée, era ante todo un patriota, que procuraba identificar a Francia con la causa humanista y por ende antirracial, al menos en lo que se refiere a los europeos, a los que plantea en esencia la hegemonía civilizacional gala. En esta línea, en su libro sobre temperamento y carácter Le Bon ataca las visiones alemanas que han interpretado la Primera Guerra Mundial como un enfrentamiento entre razas europeas, haciendo prevalecer el patriotismo humanista de indudable, para él, fundamento galo ${ }^{34}$.

Para concluir, hemos comprobado que existía una tendencia muy ambigua en lo que podríamos llamar el espectro cultural de la raciología. Cierto que se rechazaba la raciología de fundamentos físicos, ya que, según los raciólogos culturalistas era imposible demostrar bajo ese criterio las diferencias entre los pueblos europeos. Sólo los caracteres morales e intelectuales podían servir para clasificar a las poblaciones del continente. En definitiva, las diferencias físicas

31 Ibidem, p.2.

32 Ibidem, p.11.

33 Ibidem, p. 15.

34 Gustave Le Bon. Tempérament et Caractère, selon les individus, les sexes et les races. París: Felix Alcan, Gème éd. S.d. 
podrían ser consecuencia de las culturales, pero no a la inversa ${ }^{35}$. A partir de aquí se hablará de "razas históricas" que gracias a diversos factores culturales acumulados a lo largo del tiempo, y a la determinación geográfica, habrían adquirido constituciones mentales fijas. Y sobre todo en el interior de las "razas históricas" se debería singularizar a sus aristocracias, en las que las diferencias individuales eran mayores que en las clases inferiores, más inclinadas a la homogeneidad colectiva. De resultas de lo anterior se infería que las elites de las razas históricas superiores, como la francesa, eran las más evolucionadas. El racismo cultural se mutaba de esta guisa en un aristocratismo nacional.

La raciología cultural acabó por encontrar su formulación definitiva en la llamada "psicología de los pueblos" que entre los años treinta y cincuenta, sobre todo, retomaba viejos conceptos acuñados desde Taine a Le Bon. Como señala Reynaud Paligot, "la herencia psicológica era una constante de los escritos de la psicología de los pueblos, al igual que tomaba distancias con los factores raciales", ya que "siguiendo una tradición antigua, remontaban a la Antigüedad, el rol del clima y las condiciones geográficas eran siempre consideradas como factor explicativo del carácter de los pueblos"36.

\subsection{El Hispanoamericanismo “antirracista” frente a la Latinidad} AFRANCESADA Y EL RACISMO NORTEAMERICANO

En los medios competenciales europeos, en los que Francia luchaba por alzarse con el liderazgo continental, una polémica muy fogosa fue la que tuvo que ver con la decadencia de las "razas latinas". Entre las naciones "latinas" se contaba a la propia Francia por derecho histórico, cuya República quería entroncar con el ideal romano. El sociólogo Gabriel Tarde (1843-1904) se planteaba en línea con ese debate si Francia, en cuanto pueblo latino, se encontraba en decadencia frente al auge de anglosajones y alemanes ${ }^{37}$. La oposición entre latinos y anglos tuvo episodios relevantes en las mentalidades españolas ${ }^{38}$. En Italia la controvertida inferioridad de los latinos movió a argumentar a la contra a los intelectuales italianos $^{39}$. El debate afectaba a Francia y la trascendía.

Precisamente para responder tanto a la concepción de la latinidad auspiciada por Francia, con el fin de liderar a las naciones mediterráneas y americanas

35 Pierre-André Taguieff. La couleur et le sang. Doctrines racistes à la française. París : Mille et Une Nuits, 2002, p.103.

36 Carole Reynaud Paligot. Races, racisme et antiracisme dans les années 1930. París : 2007, p.72. Véase igualmente : Carole Reynaud Paligot. La république raciale, 1860-1930. París : PUF, 2006.

37 Gabriel Tarde. Sur la prétendue décadence des peuples latins. Conférence faite à l'Athenée de Bordeaux le 21 mai 1901. Bordeaux : Imprimerie G.Gounouilhou, 1901.

38 Lily Litvak. Latinos y anglosajones: orígenes de una polémica. Barcelona : Puvill, 1980.

39 Napoleone Colajanni. Latins et Anglo-Saxons. Races Supérieures et Races Inférieures. París: Felix Alcan, 1905. 
consideradas afines cultural y políticamente, como también de contradecir al Manifest Destinity norteamericano, que concedía Estados Unidos un papel de vanguardia mesiánica en la emancipación americana, surgirá la ideología hispanoamericanista. Mas, el hispanoamericanismo como ideología racial -la "raza hispana"- auspiciada desde España, con la estrecha colaboración de las elites criollas de las repúblicas latinoamericanas "hermanas", fue interpretada en su época por un pequeño número de intelectuales, entre los que destaca el cubano Fernando Ortiz (1881-1969), como una variante del racismo cultural. Así veía el asunto Ortiz:

«En la comunicación-circular dirigida por la Universidad de Oviedo á los centros docentes de la América de habla española, saludaba aquella a éstos, en nombre de la comunidad de raza, primero, y después, en segundo lugar, 'de la fraternidad intelectual' ¿Por qué esta anteposición de la raza a la mentalidad? (...) El español contemporáneo, que en América ha buscado mercado para sus industrias o ambiente para sus mercancías o que aceptemos su influencia espiritual, no por la bondad y méritos de unas y otras, sino por razón de raza. Invertidos los términos, el éxito sería halagador: enviarán mercaderías insuperables y literatura insustituible o utilísima por lo menos y el interés de la raza estaría asegurado”.

Localiza Fernando Ortiz en la raza una razón intelectual que pretende perpetuar el colonialismo a través de nuevas formas de imperialismo: "No se extrañe, pues, que hoy el principio antropológico de raza, aun siendo socialmente una ilusión, como lo fue el principio religioso ayer, sea un vigorizante y sustituto ideológico del imperialismo" ${ }^{40}$. Frente a la raza como motivo conductor de la Hispanidad, Ortiz alzaba la bandera de la civilización y del antirracismo.

Ortiz sabe bien de lo que habla, ya que había realizado gran parte de su formación en España y en Italia. Afinando sus argumentos apunta a la actualidad de la raza cultural:

"El error español es explicable. Pese a los esfuerzos de generosos sociólogos contemporáneos, parece que existe un recrudecimiento del racismo gobinista (...). El pangermanismo y el paneslavismo son tendencias acentuadas de la política europea, traducidas en una expresión étnica. La discusión de la decadencia latina y de la superioridad sajona por los Sergi, Fouillée, Colajanni, Desmoulins, etc.; los acudimientos antisemitas, las disensiones austrohúngaras, la cuestión irlandesa y la

40 Fernando Ortiz. La reconquista de América. Reflexiones sobre el panhispanismo. Sociedad de Ediciones Literarias y Artísticas: París, 1911, p.22. 
candiota, la prohibitiva legislación de inmigración china y cien hechos más demuestran que las cuestiones de raza están a la orden del día”.

Mas el argumento de Ortiz no sólo se dirige al encuentro con la sociología francesa, sino que apunta directamente hacia Alemania que había alimentado su racismo con el nacionalismo romántico a la manera de Fichte. Todos los racismos, incluidos los que presentan como antirracismos, para Ortiz se subsumen en uno solo. El cubano se nos presenta de esta manera como un avanzado de la crítica a las "razas históricas".

Pero ahora viene la sorpresa, al señalar Ortiz otra paradoja in extremis: que algunos de los más conspicuos promotores en Espańa del hispanoamericanismo eran avant la lettre anticolonialistas, sobre todo movidos por la oposición al imperialismo estadounidense:

"El heraldo de esta empresa nacional [Rafael] Altamira-escribe Ortiz-, fue traductor al castellano de los Discursos de Fichte, traducción que llevó a cabo a raíz de los sucesos de 1898, y que tenía por tanto un verdadero significado histórico. Él, como todos los demás caudillos del neoracismo, como [Rafael María de] Labra, por ejemplo, desdobla el problema en dos aspectos, uno interno: la consolidación interior por obra principal de la enseñanza; y otro extremo: la consolidación de la personalidad por obra de una diplomacia de concentración étnica, dirigida a los núcleos afines; exactamente como propagara Fichte. Así vemos a Altamira y a Labra, por no salirnos de los principales americanistas españoles, luchando contra el presente atraso mental de Espańa, pintado por ambos y especialmente por el primero con los más negros colores y promoviendo una corriente de opinión en pro de lo que sin peligro de impropiedad pudiera llamarse el 'panhispanismo', llamado a luchar contra el 'panamericanismo', así como a los pedagógicos consejos de Fichte se unieron sus arengas 'pangermanistas', destinadas a contrarrestar la acción expansiva de las otras razas" ${ }^{41}$.

Los autores concernidos por Fernando Ortiz en las críticas de neorracismo, Rafael María de Labra y Rafael Altamira, a pesar de su anticolonialismo político, identificado con el liberalismo progresista, estarían afectados por la idea de "raza histórica” amasada en el mundo francés por los conservadores Fouillée y Le Bon. Sin ir más lejos, Altamira había aplicado el método de Fouillée-Le Bon a los españoles en un libro capital suyo: Psicología del pueblo español, publicado en $1902^{42}$.

42 Rafael Altamira. Psicología del pueblo español. Madrid: Biblioteca Nueva. Introducción de 
Identificado el panhispanismo, por Fernando Ortiz, como una nueva corriente de hegemonía racial que buscaría restablecer soterradamente el dominio neocolonial, se pregunta ańos después, en pleno auge de los racismos fascistas, sobre si existe en verdad la idea misma de raza:

“¿Qué es una raza? A los neorracistas españoles, que por un fenómeno paradójico pretenden hallar la salvación de España en donde nadie la habría imaginado ¡en la raza! debiera serles muy fácil definir la raza hispana, único medio de convencernos de su virtualidad social. Y, sin embargo, so pena que den al traste con todos los estudios modernos, no podrán decirnos más que vaguedades, las mismas que nublan hoy el racismo científico (...). La naturaleza no crea razas, como no crea especies ni géneros; el hombre los inventa para sus fines científicos, sociales, políticos, religiosos, etc. Así que ya desde ahora puede verse lo inestable del concepto de la raza, que no es sencillamente más que una agrupación de seres desde determinados puntos de vista diferenciales" ${ }^{\sharp 3}$.

Si el antirracismo lo aplicó Ortiz al dominio de las relaciones entre España y América en los años diez y veinte del XIX, más adelante congruentemente se mostró firmemente antirracista frente a los movimientos de los años treinta ${ }^{44}$. Para finalizar, Fernando Ortiz resumiría todos sus análisis y experiencias sobre la raza en un grueso volumen publicado en 1946, al final de la Guerra Mundial, elocuentemente titulado El engaño de las razas ${ }^{45}$. Con él se ponía en profunda sintonía con la antropología del germano-norteamericano Franz Boas, al negar cualquier realidad no sólo al racismo biológico, enarbolado por los nazis y sus aliados $^{46}$, sino al cultural, de orígenes más inciertos y sutiles. Sólo una posición como la caribeña, encarnada en don Fernando Ortiz, podía contemplar la perversión que encerraba el racismo antirracista basado en criterios "culturales".

Mas, más allá de la teoría, los combates antirraciales de Ortiz tuvieron un origen muy concreto, experiencial, que relata en dos anécdotas. Una en las Baleares cuando era jovencito, donde tuvo por compañero a un niño nubio liberto: "Fuimos buenos camaradas infantiles y a ninguno en la escuela se le ocurrió jamás que el negrito, a quien por su color llamábamos Cabeza de Moro, fuese sin embargo de distinta humanidad" 47 . En otra ocasión su abuelo lo llevó a

Rafael Asín Vergara, 1997 (orig.1902).

43 Ortiz, op.cit. 1911, pp.12-13.

44 Fernando Ortiz. Defensa cubana contra el racismo antisemita. La Habana: Asociación Nacional contra las discriminaciones racistas, 1939.

45 Fernando Ortiz. El engaño de las razas. La Habana: Ed. Páginas, 1946.

46 Franz Boas. Anthropology and Modern Life. Nueva York: Dover, 1986 (orig. 1928).

47 Fernando Ortiz. "Martí y las razas". In: Fernando Ortiz. Etnia y sociedad. La Habana: 
ver en Cuba al general Martínez Campos, que a él le pareció mulato, cosa que le extrañó siendo español. Estos hechos complicaron su ingenuidad infantil. Pero lo que más lo afectó fue que su abuelo esgrimía con frecuencia argumentos racistas para descalificar a sus contemporáneos. Sobre José Martí, que por cierto no tenía ni mancha de sangre negra, un buen día le dijo su abuelo: "Martí no era de color, pero como si lo fuera; ese fue mulato por dentro'. Y entonces comprendí que en mi tierra el color oscuro en la piel llevaba implícitamente consigo una prejuiciosa consecuencia de inferioridad y vilipendio social transida de injusticias y dolores. Hasta las almas se las suponía negras cuando se las quería envilecer". Como puede comprobarse determinadas situaciones estructurales, percibidas en la contradictoria Cuba que te tocó vivir a Fernando Ortiz, le permitieron intuir los laberintos y falsas salidas de la concepción cultural de la raza, y lo inclinaron hacia un antirracismo mucho más analítico que el de la pura denuncia ideológica.

El uso antirracista de la raza, en toda su condición paradójica, se puede seguir igualmente en Estados Unidos. Se ha puesto como ejemplo paradigmático de segregación invisible el caso del sociólogo mulato W.E. Burghardt Du Bois (18681963). Du Bois vinculó su temprana trayectoria biográfica por las universidades americanas al destino común de todas las gentes de color. Como estudiante y profesor ayudante pasó en el fin de siglo XIX por universidades tales como Harvard y Atlanta. Du Bois, narró su experiencia segregacionista en los campus en un libro que por segura necesidad, dado el vacío ejercido en torno a él, se autoeditó en 1940: Dusk of Dawn: An Essay toward an Autobiography of a Race Concept $t^{48}$. En él relacionaba la trayectoria biográfica, de su sinuosa segregación, con el concepto de raza. Toda su experiencia la revirtió positivizando la noción de "raza", que ahora reclamaba como un signo de la identidad "negra".

En otra obra, The Souls of Black Folk, libro aparecido en 1903, Du Bois deambula a través de un sistema de tesis, antitesis, síntesis, típicamente hegeliano, en derredor de la noción de "alma", y sobre todo de "raza". Para Du Bois, los hombres y mujeres "de color" deberían reivindicar la "raza" como un elemento unificador de la "nación". La raza para Du Bois se definiría, frente al empleo que hicieron de ella los racistas, por el "color" y no tanto por factores fisiológicos. "El interés por este concepto era el poder designar un modelo de identidad africano-americana claramente distinguida de, e incluso opuesta a, una identidad americana blanca y homogénea”. Pero ante la posible confusión con el término raza, empleado entonces por los racistas, en plena alza por el éxito del eugenismo, "la construcción de una identidad cultural en el sentido extenso, histórico de una parte y literario de otra, por oposición a una identidad natural,

Editorial de Ciencias Sociales, 1993, p.111.

48 W.E.B. Du Bois. The autobiography of W.E.B. Du Bois. A Soliloquy on Viewing My Life from the Last Decade of Its First Century. New York:, Internacional Publishers, 1968. 
es esencial para designar las representaciones estereotípicas racistas que reposan bastante frecuentemente en la idea de una "natura" blanca o negra, estática y eterna" ${ }^{49}$. Había invertido en esta trayectoria el significado de la palabra "raza" para darle, como ocurría en América Latina, una connotación reivindicativa. La "raza” sería ahora la fuerza de lo excéntrico. En esto venía a coincidir Du Bois de hecho con lo que ocurría en América Latina, donde la fiesta de la "raza" se había acabado convirtiendo en una celebración nativista, cargada de reivindicaciones autoctonistas $^{50}$. En franca contradicción con estas posiciones "prorraciales" de Du Bois otro sociólogo negro, William Julius Wilson, circunscribió poco después el problema racial a un simple asunto de estratificación y jerarquía social. A pesar de su autoproclamado "marxismo" Du Bois no coincidía con el clasismo de Wilson, más en consonancia con el materialismo histórico.

\section{De las campañas antirracistas de la UNESCO a la PERVIVENCia} ANALÍTICA DE LA PSICOLOGÍA DE LOS PUEBLOS

La movilización intelectual antirracial alcanzó su punto álgido en Estados Unidos, antes de la Segunda Guerra Mundial, gracias a los seguidores académicos de Boas, opuestos de manera militante a la raciología nazi y fascista ${ }^{51}$. Este combate se prolongó tras la guerra en la UNESCO, el organismo cultural y educativo de la recién creada ONU. Entre los antropólogos que ocuparon posiciones relevantes en la UNESCO hay que resaltar al antropólogo Alfred Métraux, pieza clave en el organismo como jefe de su División para el Estudio de la Raza. Por encargo de la ONU, éste había realizado en 1949 una campaña de información sobre la inconsistencia de los prejuicios raciales. En paralelo en 1949 fue aprobado por la UNESCO el primer texto resultante de su activa política antirracial, el cual tuvo rápido alcance internacional. El relator y principal artífice de aquella primera declaración fue otro conocido partidario del antirracismo biológico, Ashley Montagu. En la declaración aparecían las firmas de Juan Comas, de México, y de Claude Lévi-Strauss, de Francia, entre otros adherentes. Mas, en todo Métraux siempre estaba entre las bambalinas ${ }^{52}$.

Quien dirigirá las andanadas más importantes de corte científico e ideológico contra la posición antirracista de la UNESCO será, paradójicamente, otro francés: Henri V. Vallois, investigador en el área de arqueología del Musée de l'Homme, y por

49 W.E.Burghardt Du Bois Les âmes du peuple noir. París : La Découverte, 2007 (orig.1903). Edición de Magali Bessone, p,299.

50 Miguel Rodríguez. Celebración de "la raza". Una historia comparativa del 12 de octubre. México: Universidad Iberoamericana, 2004.

51 J.A. González Alcantud Sisifo y la ciencia social. Variaciones criticas de la antropología. Barcelona : Anthropos, 2008, pp.40-55.

52 d AA.VV. Le concept de Race. Résultats d'une enquête. París, UNESCO, 1953. AA.VV. Le racisme devant la Science. París : UNESCO, 1960. 
tanto compañero en cierta medida de Alfred Métraux. No es de extrañar la posición de Vallois, ya que poco antes, en 1948, él mismo se había pronunciado motu propio señalando que había que ponerse en guardia por el abuso del término "raza": "Parece de principio claramente que la raza no debe ser confundida con las organizaciones políticas que son los estados y las naciones". Incluso el empleo de la palabra "raza francesa". "Desde el punto de vista antropológico, esto no tiene sentido", afirma. "Francia tiene al menos tres razas que separan claramente sus caracteres físicos", apostilla ${ }^{53}$. Se inclinará Vallois, por lo tanto, por la restricción del término raza a sus usos biológicos, para evitar su fácil politización. Dará acogida a sus críticas la revista antropológica británica $M a n^{54}$. Paralelamente, un librito divulgativo de Vallois sobre las razas, publicado en la popular colección Que sais-je?, alcanzó los 90.000 ejemplares de difusión en varias ediciones, lo que vino a subrayar la fortuna y eco del término raza en Francia aún después de la Segunda Guerra Mundial ${ }^{55}$.

A raíz de esta ofensiva, que básicamente cuestionaba el primer antirracismo de posguerra, la UNESCO convocaría en 1954 una reunión en Moscú, en la que los biólogos eran mayoría, para sancionar, matizar o corregir lo que los antropólogos habían sostenido en anteriores reuniones. El ataque de los contrarios, de principio, se centraba en la composición del comité "antirracista", de cuyos ocho miembros, denunciaba Vallois, sólo dos eran propiamente antropólogos físicos, siendo el resto historiadores, filósofos y sociólogos. Esta vez, para compensar, la mayoría fueron antropólogos físicos, genetistas y zoólogos. En esta reunión, de 1954, en la que las críticas de Vallois estuvieron encima de la mesa, se pretendía denunciar "las impresiones, las incertidumbres e incluso las inexactitudes de algunos de los argumentos invocados" 56 .

"La declaración que allí se elaboró -cuenta Vallois- estaba naturalmente, como la precedente, netamente opuesta a las tesis racistas, pero, a diferencia de aquella, lejos de investigar para desacreditar a la raza, prefería poner el acento sobre la oposición fundamental entre esta categoría, de la cual se esforzaba en precisar los límites y la significación, y las categorías de naturaleza cultural o social. Guardaba una prudente reserva sobre la importancia racial de los caracteres psicológicos y de la hibridación. Se pasaron en silencio, como estando fuera de su objetivo, las nociones de orden filosófico sobre el instinto innato de cooperación o ético de fraternidad universal"57.

53 Henri Vallois. Les races humaines. París : PUF, 1948, p.7.

54 Henri Vallois. "U.N.E.S.C.O. o Race”. Man, 1951. Vol.LI, pp.15-16.

55 Reynaud, op.cit. 2007, p.25.

56 Henri Vallois. "Race et racisme. La Troisième Conférence de l'U.N.E.S.C.O. (Moscou, 1964)". L'Anthropologie, Tome 69, no1-2,1965, p. 84.

57 Ibidem, p.85. 
El texto resultante dio lugar a nuevas discusiones, con sugerencias ańadidas, que lo volvieron, al decir de algunos críticos, "pesado" y "ambiguo".

Las autoridades de la UNESCO, conscientes de las repercusiones de la problemática y de sus laberintos, querían diluir las ambigüedades. También, en apoyo de nuevas reuniones concurrió el que se actualizase la cuestión racial ante la opinión pública mundial de los ańos sesenta, sobre todo gracias a movimientos como el Black Power en Norteamérica y la négritude en Africa, y sobre todo el movimiento contra el apartheid en Sudáfrica. En este marco un nuevo reencuentro tuvo lugar París en 1966. Ahora eran mayoría historiadores, antropólogos, sociólogos y filósofos. Al final de la declaración del 66 se manifiestan los veinticuatro científicos reunidos, de manera clara, tajante y sin ambigüedades contra las tesis racistas. En la declaración es de destacar los ascos que le hacen los reunidos a la propia palabra "raza" que ahora va siendo sustituida automáticamente por "poblaciones", "grupos étnicos" o "culturas". H. Vallois se posiciona entonces, como lo hizo ya en 1951 en $M a n$, contra ese ocultamiento semántico de la propia palabra raza, política que llama "del avestruz". A las cosas, aduce Vallois, habría que llamarlas por su nombre y no se tendría por qué enmascararlas. Ocurre, sin embargo, que la crítica de Vallois escondía no sólo de una cuestión semántica, sino de fondo.

Lo que nunca se ha planeado la UNESCO, cuya sede se encuentra en París, y ha sido muy hegemonizada por el mundo francófono desde sus inicios, es el problema que suscitan las razas que hemos catalogado de "culturales". De hecho la corriente de "psicología de los pueblos", donde se ha refugiado el culturalismo racial continuó muy activa tras la Guerra Mundial en la propia Francia. La escuela de pensamiento sobre la psicología de los pueblos, abierta en París por Émile Boutmy, del cual ya hablamos más arriba, será continuada por André Siegfried (1875-1959). Siegfried pertenecía a una familia de banqueros de Le Havre. Fue nombrado profesor de la École Libre des Sciences Politiques en 1910, institución que en 1945 se convertirá en el Institut des Sciences Politiques de París ${ }^{58}$. Fue editorialista igualmente del diario conservador Le Figaro. Su obra de reflexión psicopolítica sobre Francia, Canadá, Estados Unidos e Inglaterra la culminó en 1950 con la publicación de L'âme des peuples ${ }^{59}$. Se ha dicho de él, después de hacer recuento de los numerosos cargos que detentó -entre ellos miembro de la redacción de la influyente revista Annales, desde su fundación, y presidente de la no menos importante Revue française de Science Politique-, que "pocos universitarios han tenido, en Francia en el curso del siglo XX, una audiencia tan extensa y una influencia tan grande, en su propio país y en el mundo entero".

58 Véanse entre otras obras iniciales de André Siegfried: A.Siegfried. La crise de l'Europe. París: Calmann-Lévy, 1935. A. Siegfried. "La psychologie des latins". Revue de Psychologie des Peuples, no 1, 1946, pp.13-22. A. Siegfried. L'âme des peuples. París: Hachette, 1950.

59 Claret, op.cit. pp.90-95. 
En cuanto a la "genialidad francesa " téngase presente que, al decir de Siegfried, «el carácter único de la psicología francesa procede justamente de la diversidad», lo cual era una idea muy repetida en la raciología cultural :

« No hay una raza francesa, hasta tal punto que la expresión, cuando se la emplea, no significa nada (...) Somos, como dice Seignobos, una raza de mestizos, pero se sabe que una selección demasiado estricta no desarrolla la inteligencia y que todas las mezclas no dan malos resultados (cursivas del autor). El pueblo francés parece ser se ha enriquecido más bien de aportaciones variadas: debemos a los latinos nuestra lucidez intelectual, nuestro don de expresión; a los celtas nuestros espíritu artístico, nuestro individualismo llegando en ocasiones hasta la anarquía; a los germanos lo que tenemos de genio organizador y constructivo ».

Las teorías de André Siegfried no dejaban de provocar contradicciones incluso entre sus propios seguidores, que no sabían cómo reaccionar, por ejemplo, ante el determinismo geográfico del maestro. La siguiente opinión registrada con motivo de un homenaje a su obra es bien elocuente, puesto que vincula el determinismo de Siegfried con posiciones ultraconservadoras limítrofes con el fascismo ${ }^{60}$. Sólo un filo hilo separaba a unos de otros.

Se ha indicado igualmente el desencuentro entre los investigadores americanos y Siegfried, a pesar de que al menos dos de las obras de éste fueron traducidas al inglés. El mismo Siegfried atacó el libro de Rodha Métraux y Margaret Mead Thèmes de culture française ${ }^{61}$, un intento de interpretación de la cultura francesa desde Estados Unidos, haciendo valer la superioridad de lo vivido sobre el método a distancia preconizado por Mead, a raíz del éxito de este método aplicado durante la Guerra Mundial a la cultura japonesa por Ruth Benedict. Atacaba Sigfried el que Mead y Métraux, que por cierto era la esposa del antropólogo francés antes mencionado, Alfred Métraux, hubiesen tomado como modelo de análisis a la burguesía francesa clásica, del periodo 1854-1914, convirtiéndola en la parte principal del estereotipo contemporáneo del francés medio ${ }^{62}$. Los estudios culturales a distancia, y los "patterns" culturales que se inferían de los mismos, es decir las características más relevantes y significativas de una cultura, agrupadas frecuentemente en ejes de coordenadas binarios, inducían peligrosamente a desplazarse frente a una suerte de neorracismo basado en el determinismo cultural. De esto ya había alertado un miembro del grupo de Benedict y Mead, Gregory

60 VV.AA. L'oeuvre Scientifique d'André Sigfried. París : Presses de la FNSP, 1977, pp.30-31.

61 Rhoda Métraux \& Margaret Mead (eds.) Themes in French Culture. A Preface to a Study of French Culture. New York: Bergham Books, 2001, pp.X-XI.

62 Kathryn M Anderson-Levitt. «Introduction to Themes in French Culture». Mead \& Métraux, op.cit, 2001, pp.XII-XIII. 
Bateson. Pero no era esto precisamente lo que molestaba a Siegfried, sino el que los franceses se hubiesen convertido en objeto de estudio casi entomológico, en lugar de serlo otros pueblos menos civilizados.

Todo este movimiento, que combinaba en diversos grados psicología colectiva y antropología de los "patterns", fue completado con la puesta en marcha en 19371938 de un Institut Havrais de Sociologie Economique et Psychologie des Peuples en Le Havre, por parte del discípulo de Siegfried, Abel Miroglio (1895-1978) ${ }^{63}$. Los trabajos de este instituto se proyectarán más allá de la Guerra Mundial, y tendrá algunos de sus más destacados y conspicuos seguidores en europeístas sin tacha como el español Salvador de Madariaga; Véase sin ir más lejos el significativo libro de éste Carácter y destino de Europa, donde vuelve sobre las lecturas psicológicas para explicar las diferencias culturales entre los pueblos europeos- ${ }^{64}$.

\section{La pulsión Jerárquica y el Multiculturalismo bienpensante, o por} QUÉ PERMANECE EL PROBLEMA DE LA RAZA

De momento, quedémonos con la idea principal que ya nos ha aparecido: la de racismo "racismo velado", "nuevo racismo", "racismo simbólico" o "racismo moderno". Se ha denominado de estas maneras al fenómeno que comienza a ser visibilizado hoy. Sintetizando la problemática se ha escrito: "Los racismos flagrantes y velados tienen dos formas de expresión contrastadas del mismo fenómeno central. El racismo flagrante es violento, estrecho y directo. El racismo velado es frío, reservado e indirecto" ${ }^{65}$. El dédalo conceptual emergido del racismo cultural se une así a las ambigüedades del racismo biológico, nunca enterrado del todo a pesar de los esfuerzos pedagógicos y propagandísticos desplegados por la UNESCO desde sus inicios.

Este "racismo cultural" tiene formulaciones paradójicas en países como Gran Bretaña, Estados Unidos y Francia, los cuales han tenido que construir su idea de ciudadanía combatiendo contra las formas más groseras del racismo, es decir el racismo biológico, o con anterioridad frente a la segregación esclavista. No obstante, las oposiciones estereotípicas entre las naciones occidentales ha provocado que éstas en competencia por limpiar su narración histórica de cualquier contaminación racista, y en pos de mostrar la idoneidad de su propia way of life, política y cultural, hayan adjudicado a las demás el vicio de ser más racistas que ellas mismas. Hartos, por ejemplo, de sentirse los responsables únicos del racismo contemporáneo, los norteamericanos, a través de sus scholars, han reaccionado buscando nuevos argumentos sospechosos de racismo en naciones sin mácula aparente, como Francia.

63 Abel Miroglio. La psychologie des peuples. París: PUF, 1962

64 Salvador de Madariaga. Carácter y destino en Europa Madrid: Espasa Calpe, 1980, (orig.1925,1929,1951).

65 Thomas F. Pettigrew \& R.W. Meertens. "Le racisme voilé: dimensions et mesure”. M. Wieviorka (ed.). Racisme et Modernité. París: La Decouvérte, 1992, p.110. 
Otra opinión es la de quienes sostienen que es un anacronismo hablar de "racismo" refiriéndonos a los procesos anteriores a la segunda mitad del siglo XIX, ya que de aplicarse el concepto en su conceptualización actual, todo el mundo en aquella época podría potencialmente ser catalogado de racista. De manera que se propone aplicar el concepto racista sólo a los movimientos sociales e intelectuales existentes a partir de los años veinte. Esta sería, en nuestra opinión, una manera de eximir de la acusación de racismo a muchos sectores, que efectivamente han jugado esa carta, frente a otros claramente antirracistas a lo largo de los siglos. El racismo no puede subsumirse en la corriente general, amoral en buena medida por ser un cúmulo de hechos objetivos, de la Historia. No es un fatum ni tampoco un hecho reciente. El racismo es una práctica de segregación consciente con su historia siniestra que late más allá de los automatismos históricos estructurales. No cabe, pues, desresponsabilizar a quienes han ejercido conscientemente el racismo o cualquier otra forma de opresión bajo el criterio de que operaban bajo unas determinadas circunstancias históricas.

\subsection{El RACISMO COMO PULSIÓN JERÁRQUiCA}

El racismo contemporáneo es una práctica soterrada, pragmática. Se parece en esto al clientelismo social y político. Existen, en el racismo como en el clientelismo, unas grandes distancias entre los aspectos normativos de la sociedad, que pueden ser abiertamente igualitarios y democráticos, y los pragmáticos, desigualitarios y jerárquicos ${ }^{66}$. Estas distancias conducen a prácticas consideradas irregulares desde el punto de vista moral, consistentes en jerarquizar a los sujetos en virtud de facies, de su apariencia física, y en los casos más sutiles, de su origen. El igualitarismo ambiente, sancionado por la ley, choca con estas prácticas jerarquizadoras. Este fenómeno produce efectos que Louis Dumont observó en el sistema de castas hindú, donde se mezclaban clientelismo y racismo.

Ya en 1900 el asunto estaba planteado tácitamente en el libro de Célestin Bouglé, Essais sur le régime des castes. Este autor decía entonces que el camino que abandonaba la "filosofía de las razas" era retomado por la "antroposociología", tan activa en su época, y a la que él se adscribía. El empirismo derivado de los estudios de campo se abría camino agraciadamente, diluyendo las fantasmagorías ${ }^{67}$. Siguiendo esa lógica el sistema de castas indio se presentaba en las antípodas del sistema de estratificación social occidental. Tomando como punto de arranque las tesis tempranas de Bouglé, Louis Dumont reflexionó ulteriormente sobre el mismo asunto en base a sus trabajos de campo en la India.

66 J.A. González Alcantud. El clientelismo social y político. Perspectiva socioantropológica. Barcelona: Anthropos, 1998.

67 Célestine Bouglé. Essais sur le régime des castes. París: PUF, 1969 (orig.1900), p.103. Prefacio de Louis Dumont. 
Dumont pensaba que uno de los primeros analistas de la casta, Max Weber, tropieza con la trampa etnicista al analizar el asunto:

"Para otros como Weber y Kroeber, la casta representa un paso al límite: el 'grupo de estatus' se transforma en casta, cuando la separación está garantizada no solamente por las convenciones y las leyes sino ritualmente (impureza de contacto) (...) Weber al incluir no sólo a los dioses distintos de la casta, sino igualmente a lo étnico, la transforma así en una "comunidad” (Gemeinschafen), "cerrada hacia el exterior, endogámica, creyente en un parentesco de sangre entre sus miembros, que se 'ponen en sociedad' (Vergesellschaflet) los unos con los otros. En suma, la casta resultaría de una conjunción entre el 'grupo de estatus' y la 'comunidad étnica"'.

Para Dumont, el caso hindú pondría en el centro del debate científico la supremacía del sistema de valores en la configuración de la jerarquía social. Dumont nos viene a señalar que el concepto de raza se ha desplazado de los aspectos físicos a la jerarquización, sosteniéndose en unos dispositivos simbólicos que la organizan en función del sistema de valores ${ }^{68}$. De ahí, la relatividad del concepto de raza, con el caso indio de fondo: "Mientras que en la India la herencia es un atributo de estatus, el racista atribuye el estatus a la 'raza"69. Para lograr su cometido Dumont adoptó en parte el punto de vista autóctono que destacaba la jerarquía bramánica y reducía el alcance del poder político, tendente al igualitarismo cívico ${ }^{70}$. No podía ser otro el punto de vista del antropólogo. El debate abierto por Louis Dumont cuestiona la organización jerárquica como base para explicar la concepción cultural de la raza.

De este debate en el que se insertan las ideas de jerarquía e igualitarismo surge la palabra clave de nuestra época: racismo. Con todas las ansiedades que provoca su empleo.

"El racismo -sentencia Dumont- es, como se lo conoce frecuentemente, un fenómeno moderno (...) La hipótesis más sencilla consiste entonces en suponer que el racismo responde, bajo una forma nueva, a una función antigua. Todo pasa como si representase, en la sociedad igualitaria, una resurgencia de esto que expresaba de manera diferente, más directa y

68 Louis Dumont. "Caste, racisme et 'stratification"”. Cahiers Internationaux de Sociologie. Vol. XXIX. París : Presses Universitaires de France, 1960, p.106.

69 Ibidem, p.109.

70 Roland Lardinois. “Genesis of Louis Dumont's Anthropology. The 1930's in French Revisited". VV.AA. Orientalism and Anthropology. From Max Müller to Louis Dumont. Pondichéry: French Institute Pondichéry, 1997, p.35. 
naturalmente, en la sociedad jerárquica. Retomar la distinción ilegítima, y tendréis la discriminación, suprimid los modos antiguos de distinción, y tendréis la ideología racista”71.

Pero no sólo la India provocaba reflexiones sobre jerarquización y racismo. Estados Unidos fue pionero en el debate sobre castas e igualitarismo. John Dollar en 1937 hablaba de sistemas de castas raciales frente a sistemas de castas estratificados, con referencia al sur norteamericano y a sus particulares estratificaciones sociales ${ }^{72}$. Siguiendo esa senda, Oliver Cox, escribe en 1948, que mientras el sistema hindú es un sistema social coherente fundado en un principio de desigualdad, el "color bar" americano contradice el sistema igualitario en el seno del cual se encuentra y constituye de alguna manera su enfermedad ${ }^{73}$. Para eludir esta complicación conceptual habría surgido el término neutro de "estratificación social" en los medios socio-antropológicos. Observadas por estos autores, las castas indias no serían un sistema tan injusto como nuestra imaginación nos las presentan, al no producir de principio violencias semejantes a la esclavitud, que ellos sí habían conocido hasta fechas muy recientes de la historia norteamericana. La esclavitud americana no daría la consideración de personas a los esclavos, pero en las castas inferiores bramánicas sí existiría esta consideración de humanidad. Cada uno de los miembros de las castas, incluidas las inferiores, se supone que aceptaría la jerarquía de nacimiento y de iniciación, estando confortablemente instalados en su nicho. Incluso, dentro de la casta se producirían movimientos matrimoniales exogámicos y solidaridades o fraternidades internas ${ }^{74}$. Lo que hace Cox es establecer una distancia insalvable entre la casta y la raza. Para él la raza se definiría esencialmente por criterios físicos, determinantes de todo punto de vista, mientras que la casta sería un mecanismo de distinción cultural, en el que intervendrían elementos tales como la construcción social de la impureza, sin relación con el concepto higiénico, o de distinción, manifestada sobre todo con los actos alimentarios de la comunidad. De esta manera se transitaría de la real y física diferencia de constitución física, fundamento del racismo biológico, a la "pureza de sangre" metafórica, presente en las castas ${ }^{75}$.

71 Dumont, op.cit. 1960, p.107.

72 John Dollar. Caste and Class in Southern Town. Nueva York, 1937.

73 Oliver C. Cox. Caste, Class and Race. A Study in Social Dynamics. New York: Modern Reader Paperbacks, (1970, orig.1948).

74 Ibidem, pp-18-20.

75 Ibidem, pp.423-428. 


\subsection{El RACISMO COMO Mito COMPETENCIAL}

Recapitulando. De de lo dicho hasta ahora cabe inferir dos conclusiones:

Primero, existe una relación estrecha de la idea de raza con la imaginería occidental, emergida de la competencia entre los pueblos europeos. La aportación que nosotros podemos hacer a este movimiento interpretativo de la idea de raza, sobre la que se han vertido infinidad de páginas, proviene del hecho siguiente: los raciólogos y racistas euroamericanos, en los que hemos centrado nuestra interpretación empírica, no medían con los pueblos extraeuropeos sus armas más que de una manera diletante. En la existencia del sistema de dominación colonial estaban casi todos de acuerdo, incluidos algunos "revolucionarios". Era con los demás países europeos, competidores directos por la hegemonía mundial, con quienes contrastaban sus argumentos los occidentales. Este es un aspecto que frecuentemente han pasado por alto los estudios raciológicos, absortos en la interpretación del otro lejano. Hoy día incluso los estudiosos del imperialismo reconocen un papel esencial en la formación del otro lejano a las tensiones y competitividades intraeuropeas o intraoccidentales.

Segundo, el antihistoricismo de la idea de raza cultural. Como fue señalado en su momento por Marcel Olender, las políticas de la raza se han fundamentado epistemológicamente en el antihistoricismo. La raza sería así una apreciación ahistórica, solidificada y constante, como sostiene claramente Gustave Le Bon, que atraviesa las edades. Nada puede sustancializarse, esgrime Olender, si no es en razón de la construcción del mito. Señala esta analista que, "si al binomio Pensar / clasificar conviene añadirle el verbo jerarquizar, la interacción entre raza y erudición llama a un cuarto asunto, contorneado de sombra y de luz: mito"76. El mito de la raza está operativo gracias a su ahistoricidad. Frente a ello Olender señala que el lingüista Fernand de Saussure oponía la única certeza que tenía: el movimiento, es decir el devenir temporal histórico.

Las posibilidades de liberarse del problema de la raza, bajo las formas más evidentes como la segregación, llevaron en Norteamérica a los teóricos universitarios a imaginar e idear el multiculturalismo, en cuanto políticas del reconocimiento practicadas desde las identidades colectivas étnicas. Las críticas a este concepto, de gran éxito mediático y político, no se han hecho esperar. Desde el lado intelectual francés se ha esgrimido, por ejemplo: "Postular una paleta de colores, un abigarramiento humano, es igualmente hacer de la asimilación o de la integración un problema y la figura del meelting pot o aquella del crisol republicano puede (...) aseverar la ineficacia" 77 . Lo cierto es que la idea de raza

76 Maurice Olender. Race sans histoire. París : Galaade-Points, 2009, p.16.

77 Jean-Loup Amselle. Vers un multiculturalisme français. L'empire de la coutume. París: Aubier, 
hoy ha retrocedido no tanto gracias a las políticas humanitaristas y antirracistas de la UNESCO, como a que los excesos de la Segunda Guerra Mundial habían abonado el terreno para que éstas tuviesen éxito. Existe, por consiguiente, una gran inquietud sobre la ineficacia de las políticas multiculturalistas. E incluso sobre la perversidad que esconden detrás de un aparente progresismo. Hoy día se ha dicho con gran razón: "El término 'raza' es en sí una engañosa ficción del siglo XIX y el término 'etnicidad' en su presumible sentido biológico es su fotocopia de finales del siglo XX. Sus rasgos son más imprecisos, pero el diseño de la imagen es igual negativo"78. La raza ha sido sustituida por el "grupo étnico", y éste por la "etnicidad", sobre todo para los convencidos de que todo universalismo ergo globalización- conlleva mil peligros para las identidades amenazadas. Constatamos hoy en la primera década del siglo XXI, que desaparecida la palabra, e incluso el concepto, no se ha eliminado el mal, el racismo. Es el camino del multiculturalismo cuanto menos un falso atajo.

A tenor de la complejidad alcanzada por el concepto de racismo, los Postcolonial Studies, surgidos en el mundo anglosajón de la mano de profesores de orígenes subalternos procedentes de antiguos territorios del Imperio británico, han venido a preguntarse sobre la existencia del "racismo cultural". Todo ello en la medida en que el racismo biológico ha ido perdiendo relevancia en la interpretación de las persistentes discriminaciones raciales. Para ello los poscolonialistas han dado más importancia a los fundamentos culturales del racismo, sometido a los dictados de la externalidad estética y de la esfera pública. De esta manera"all racism has its roots in, and is explainable by, categories of culture"79. A partir de esas hipótesis culturalistas se podrían establecer unas retóricas postcoloniales, como casa común para excolonizadores y excolonizados. De hecho, así se entendería que los principales portadores del antirracismo colonial fuesen los negros americanos, capaces de haber insertado su discurso en la idea de modernidad ${ }^{80}$. La obra de Frantz Fanon Les damnés de la Tèrre, donde el psiquiatra martiniqués desarrolla su teoría de la inferiorización patológica de los colonizados, necesitados de desprenderse de este complejo mediante un acto de voluntad política en el que violencia es parte central ${ }^{81}$, se convierte por estas razones en un elemento axial de los Post-Colonial Studies. Esta posición fanoniana puede conducir entre otras cosas a reforzar el africanocentrismo. La superioridad racial de los negros africanos estaría demostrada incluso, para

1996 , p.18.

78 Gerd Bauman. El enigma multicultural. Un replanteamiento de las identidades nacionales, éticas y religiosas. Barcelona: Paidós, 2001, p.35.

79 Laura Chrisman. Postcolonial Contraventions. Cultural Readings of Race, Imperialism and Transnationalism. Manchester: Manchester University Press, 2003, p.130.

80 Ibidem, p.91.

81 Frantz Fanon. Los condenados de la tierra. México: FCE, 10a 1988. 
los partidarios de la negritud extrema, por la presencia de la melanina en la piel; afirmación, en definitiva, que hace prevalecer irónicamente la inferioridad racial de Occidente ${ }^{82}$. Incluso se ha señalado, que según estas teorías, sólo "un negro tiene el derecho a decirlo él mismo, porque con ello afirma todo lo que percibe despreciado por los otros", "pero que el blanco no tiene derecho a decírselo al reenviar a su "esencia" supuesta: esto es el racismo" 83 . A la vista de esta complejidad, tal como Benedict avanzó durante la Guerra Mundial la educación no es el camino más adecuado, sobre todo si la apuesta por éste supone abandonar la "ingeniería cultural" ${ }^{84}$.

¿Qué hacer, entonces, atrapados como estamos entre la banalidad multicultural y la amenaza de las identidades excluyentes de orígenes subalternos? Ante la imposibilidad de atrapar el problema dentro de fronteras bien constituidas se alza la autoirrision, que acaban disminuyendo el valor explicativo del estereotipo y por supuesto de la idea de raza, de manera que ésta se ve limitada en su negatividad originaria ${ }^{85}$. Un ejemplo concreto de humor autoirrisiorio relacionado con los usos de los estereotipos europeos lo ofreció en los años sesenta René Cousinier, un comediante francés. En la contraportada de uno de sus discos el comentarista describe su método de la siguiente manera:

\footnotetext{
"René Cousinier es un "broma” del señor serio. Es también un señor serio que se ha vuelto muy divertido. Hablando de los orígenes de los pueblos, inspirándose en la Biblia del Talmud o en el Corán para demostrarnos que todos somos hermanos, R.C. ha llegado a trazar un irresistible cuadro de estos antagonismos humanos. La fuerza del verbo tiene toda la importancia en RC: es una ola de afirmaciones, de demostraciones, de paréntesis con un retorno detrás a una lógica y un encadenamiento en los que llega a faltarnos el aliento. Y el reír irresistible, llevado, ganado a pesar vuestro, por la precipitación de un vocabulario 'muy particular' que hace de R.C. un cuentista, un moralista de una originalidad agresiva donde el auditorio está dominado, disminuido" ${ }^{86}$.
}

Cuando satiriza el ser "français" saca a relucir las diferenciaciones entre los "franceses de Francia" y los belgas o los suizos francófonos. Ciertos de sus temas

82 Stephen Howe. Afrocentrism. Mythical Past and Imagined Homes. Londres : Verso, 1998, pp.265-274.

83 Catherine Coquery-Vidrovich. Enjeux politiques de l'Histoire coloniale. Marsella: Agone, 2009 , p.163.

84 Ruth Benedict. Race: Science and Politics. New York: The Viking Press, 1957.

85 J.A. González Alcantud. Los combates de la ironía. Risas premodernas frente a excesos modernos. Barcelona: Anthropos, 2006.

86 René Cousinier. Con ou pas con. Disco vinilo, 1969. 
son "Nous les français", "Pourquoi les allemands?", "Ceux qui ne nous aiment pas: les italiens, les espagnols, les anglais", "Les allemands nous aiment", "Différence entre l'intelligence française et l'intelligence allemande". En un momento de su frenético monólogo suelta el humorista: "No hay una raza francesa como no hay una raza alemana...Ummm. Entiendo el silencio brutal de la sala" "Si creéis que hay una raza francesa debéis coger un francés de Marsella, un verdadero francés de Marsella...Luego tomas uno de Estrasburgo... Tomáis uno de norte de Francia, con los ojos azules, y dice 'Nosotros los latinos'.

CODA de 2014

Con humor o sin humor, tres años después de escrito este artículo, el autor, al igual que cualquier ciudadano europeo, sigue comprobando la pervivencia tozuda del racismo cultural. Las campañas en el medio académico francés poniendo de relieve la existencia de verdaderos "zoos humains" en los ańos treinta para divertimento de la población parisina que acudía a la Exposición Colonial de Porte Dorée ${ }^{87}$, no ha pasado de ser una curiosidad con repercusiones acaso museográficas, pero sin trascendencia en el campo político ${ }^{88}$. Así un ministro del interior adscrito a la izquierda no tiene empacho en organizar verdaderas razzias en nombre de la ley republicana gala para expulsar y aislar a los gitanos. El racismo sigue más vivo que nunca, en plena crisis, los estereotipos mandan, y no garantizan una explicación simple a problemas complejos, una vez más. La desazón abruma a las personas de buena voluntad. No es posible que la historia se repita, no es posible que en nombre de la racionalidad burocrática, como en la época de la shoah, retornen los viejos demonios. Las ciencias sociales tienen que estar comprometidas para evitar este nuevo dislate. Hace falta mucha ingeniería cerca de la política. Ya que la militancia antirracista como la educación son importantes pero no suficientes.

87 P.Blanchard, N.Bancel et alii (eds.). Zoos humains et exhibitions coloniales. 150 ans d'invention de l'autre. París : La Découverte, 2011.

88 Pascal Blanchard et alii. Exhibitions. L'invention du sauvage. París : Musée du Quai Branly $\&$ Actes Sud, 2011. 